\title{
Dementia in the General Hospital Athanasios Douzenis
}

\author{
Address: 2nd Department of Psychiatry, Attikon Hospital, Athens University Medical School, Greece \\ from International Society on Brain and Behaviour: 3rd International Congress on Brain and Behaviour \\ Thessaloniki, Greece. 28 November - 2 December 2007 \\ Published: 17 April 2008 \\ Annals of General Psychiatry 2008, 7(Suppl I):S2I doi:I0.II86/I744-859X-7-SI-S2I
}

This abstract is available from: http://www.annals-general-psychiatry.com/content/7/SI/S2 I

(c) 2008 Douzenis; licensee BioMed Central Ltd.

Dementia is a serious disorder that appears with increasing frequency in elderly individuals. The elderly are also using the health services more frequently and to a greater extent. It is not unusual for dementia to remain undiagnosed in the early stages of the disease. Admission of an elderly individual for a physical reason, can offer a great opportunity for the diagnosis of dementia. The aim was to review the scientific literature regarding the diagnosis and treatment of a demented patient in the General Hospital and to review easy to administer and reliable screening instruments for the detection of dementia. The scientific literature on the subject is limited. Despite that, there are strong indications that patients with dementia have longer admissions, greater mortality and receive more neuroleptics than non demented patients of the same age and with a similar physical ailment. The most commonly used instruments for the detection of dementia are the "Mini Mental State", the "Clock drawing test" and history taking.

Conclusively, the admission to the General Hospital offers an opportunity for the early detection of dementia. Medical and surgical specialties need to be sensitized and trained in order to detect symptomatology indicative of dementia and refer the patient to the liaison psychiatric team. 